\title{
PENENTUAN STRATEGI BISNIS MELALUI ANALISIS SWOT PADA JAXS BARBERSHOP DI KOTA MAKASSAR
}

\author{
Syamsul Alam \\ STIE Nobel Indonesia \\ email: syamsalam74@gmail.com
}

\begin{abstract}
Abstrak
Penelitian ini menggunakan analisis SWOT dengan pendekatan kuantitatif untuk pengembangan strategi yang dapat digunakan oleh Jaxs Barbershop dalam menjalankan strategi bisnisnya. Indikator SWOT dikembangkan untuk analisis lebih lanjut dalam ukuran indikator signifikan kemampuan perusahaan untuk menangani perusahaan lain yang mengembangkan bisnis serupa.

Penelitian ini menemukan beberapa indikator ternyata cukup signifikan. Selanjutnya, pada grafik SWOT yang dilakukan berdasarkan perhitungan kuantitatif dengan bantuan program exel microsoft diketahui bahwa Jaxs Barbeshop ada di kuadran yang berarti strategi pendukung.
\end{abstract}

Kata kunci: Strategi bisnis dan Analisis SWOT.

\section{Abstract}

This research uses SWOT analysis with quantitative approach for strategy development that can be used by Jaxs Barbershop in running its business strategy. The SWOT indicators are developed for further analysis in a measure of the significant indicators of the company's ability to deal with other companies that develop similar businesses.

This research found some indicators turned out to be quite significant effect. Furthermore, in the SWOT charts performed based on quantitative calculations with the help of microsoft exel program it is known that Jaxs Barbeshop is in quadrant one which means support strategy

Keywords: Business strategy and SWOT analysis.

\section{PENDAHULUAN}

\section{A. Latar Belakang}

Usaha pangkas rambut dewasa ini lebih dari sekedar memotong rambut. Interaksi dengan konsumen untuk membuat konsumen nyaman merupakan aspek penting dalam usaha ini. Kepribadian pemangkas rambut tidak kalah pentingnya dengan keahlian dalam memotong rambut. Setidaknya itulah gambaran awal untuk menganalisa usaha pangkas rambut agar mendatangkan keuntungan maksimal.

Usaha pangkas rambut merupakan usaha yang bergerak dalam pelayanan jasa. Karena itu, pelaku usaha dibidang ini harus benar-benar memperhatikan karakteristik jasa sebagai produk yang dipasarkannya. Pelaku usaha harus teliti dan membutuhkan ketenanagan dalam pemotongan rambut karena kalau salah dalam memotong tidak bisa di betulkan lagi.

Perkembangan masyarakakat yang semakin menuntut sisi estetika dari penampilannya, termasuk dalam hal potongan rambut, menjadi pemicu munculnya bisnis pemotongan rambut dengan berbagai fasilitas yang ditawarkan. Dalam konteks inilah, akan timbul persaingan usaha karena para 
pelaku usaha di bidang ini sedapat mungkin untuk menawarkan berbagai kelebihan dan fasilitas yang melebihi para pesaingnya.

Untuk dapat memenangkan persaingan, para pelaku bisnis harus mampu menyusun perencanaan strategi bisnis yang tepat. Salah satu alat analisis dasar dalam perencanaan adalah dengan menggunakan metode SWOT. Metode SWOT menganalisis internal kekuatan (strengths) dan kelemahan (weaknesses) serta analisis ekternal peluang (opportunities) dan ancaman (threats). SWOT merupakan cara sederhana untuk memperkirakan cara terbaik untuk melakukan strategi. Implementasi SWOT sangat bergantung dengan situasi dan kondisi, baik itu situasi kondisi internal maupun eksternal. Agar mencapai hasil yang maksimal dalam analisis SWOT, Anda harus mampu merangkum berbagai indikasi yang digunakan untuk menghitung analisis SWOT itu sendiri.

Analisis SWOT bekerja dengan cara menganalisis dan memilah hal-hal yang mempengaruhi keempat faktor SWOT, kemudian diterapkan dalam gambar matrik SWOT. Dalam matrik tersebut dapat dibandingkan bagaimana kekuatan (strengths) mampu mengambil keuntungan (advantage) dari peluang (opportunities) yang ada, bagaimana cara mengatasi kelemahan (weaknesses) yang mencegah keuntungan (advantage) dari peluang (opportunities) yang ada, selanjutnya bagaimana kekuatan (strengths) mampu menghadapi ancaman (threats) yang ada, dan bagaimana cara mengatasi kelemahan (weaknesses) yang mampu membuat ancaman (threats) menjadi nyata atau menciptakan sebuah ancaman baru.

Tujuan utama dari analisis SWOT adalah untuk mengotimalkan kekuatan anda dan meminimalkan kelemahan diri, serta memanfaatkan peluang yang muncul dan menangatasi ancaman yang datang. Di dalam dunia bisnis, perubahan kondisi dan situasi akan sering anda temui. Perubahanperubahan ini lah yang harus anda sikapi dengan cara menganalisis SWOT anda agar bisnis yang anda jalankan dapat bertahan.

Penelitian ini menganalisis strategi yang tepat untuk diterapkan oleh Jaxs Barbershop sebagai salah satu tempat atau bisnis pemotongan rambut yang ada di kota Makassar. Analisis ini menemukan point pentingnya seiring dengan makin maraknya bisnis sejenis yang tentu saja menawarkan berbagai fasilitas dan keunggulannya masingmasing.

\section{B. Tujuan Penelitian}

Berdasarkan latar belakang di atas bahwa perusahaan mengembangkan strategi melalui analisis SWOT, maka tujuan penelitian adalah:

1. Untuk menganalisis indikatorindikator dari analisis SWOT yang memeiliki pengaruh signifikan terhadap pengembangan strategi Jaxs Barbershop di Kota Makassar.

2. Untuk menganalisis strategi yang paling tepat diterapkan oleh Jaxs Barbershop berdasarkan anlisisSWOT.

\section{TINJAUAN PUSTAKAS}

\section{A. Strategi Bisnis}

Perumusan strategi merupakan proses penyusunan langkah-langkah ke depan yang dimaksudkan untuk membangun visi dan misi organisasi, menetapkan tujuan strategis dan keuangan perusahaan, serta merancang strategi untuk mencapai tujuan tersebut dalam rangka menyediakan customer value terbaik. Beberapa langkah yang perlu dilakukan perusahaan dalam merumuskan strategi, yaitu:

1. Mengidentifikasi lingkungan yang akan dimasuki oleh perusahaan di masa depan dan menentukan misi perusahaan untuk mencapai visi yang 
dicita-citakan dalam lingkungan tersebut.

2. Melakukan analisis lingkungan internal dan eksternal untuk mengukur kekuatan dan kelemahan serta peluang dan ancaman yang akan dihadapi oleh perusahaan dalam menjalankan misinya.

3. Merumuskan faktor-faktor ukuran keberhasilan (key success factors) dari strategi-strategi yang dirancang berdasarkan analisis sebelumnya.

4. Menentukan tujuan dan target terukur, mengevaluasi berbagai alternatif strategi dengan mempertimbangkan sumberdaya yang dimiliki dan kondisi eksternal yang dihadapi.

5. Memilih strategi yang paling sesuai untuk mencapai tujuan jangka pendek dan jangka panjang. (Hariadi, 2005).

Strategi adalah hal menempatkan arah kepada manajemen dalam arti orang tentang sumber daya di dalam bisnis dan tentang bagaimana mengidentifikasikan kondisi yang memberikan keuntungan terbaik untuk membantu memenangkan persaingan didalam pasar". Empat tingkatan strategi, yaitu: enterprise strategy, corporate strategy, business strategy dan functional strategy.

Menurut Porter, ada tiga landasan strategi yang dapat membantu organisasi memperoleh keunggulan kompetitif, yaitu keunggulan biaya, diferensiasi, dan fokus. Porter menamakan ketiganya strategi umum. Keunggulan biaya menekankan pada pembuatan produk standar dengan biaya per unit sangat rendah untuk konsumen yang peka terhadap perubahan harga. Diferensiasi adalah strategi dengan tujuan membuat produk dan menyediakan jasa yang dianggap unik di seluruh industri dan ditujukan kepada konsumen yang relatif tidak terlalu peduli terhadap perubahan harga. Fokus berarti membuat produk dan menyediakan jasa yang memenuhi keperluan sejumlah kelompok kecil konsumen.

Porter (1993) menyatakan bahwa diferensiasi dipahami melalui sejumlah kegiatan spesifik yang dilakukan perusahaan dan pengaruh kegiatan tersebut terhadap pembeli. Diferensiasi tumbuh dari rantai nilai perusahaan. Setiap aktivitas nilai yang ada dalam perusahaan merupakan sumber yang potensial bagi penciptaan keunikan bagi perusahaan. Sejumlah faktor yang membantu diferensiasi dapat diperoleh dari cakupan bersaing yang luas, yaitu kemudahan pemeliharaan bagi pembeli jika dibandingkan produk sejenis yang ada di segmen pasar dan keunggulan kompatibilitas dibandingkan dengan produk lain. Sebagian besar manfaat tadi hanya dapat dicapai jika perusahaan melakukan aktivitas rantai nilainya secara konsisten dan terkoordinasi. Jika perusahaan mengelola hubungan dengan pembeli melalui rantai nilai perusahaan secara konsisten dan berkesinambungan, maka keuntungan yang diperoleh adalah perusahaan akan memperoleh keunggulan bersaing yang berkesinambungan dan pada akhirnya bisnis perusahaan akan berkembang.

Diferensiasi

biasanya

membutuhkan biaya tinggi. Perusahaan seringkali harus mengeluarkan biaya untuk menjadi unik karena untuk mencapai keunikan, perusahaan harus melaksanakan sejumlah aktivitas nilai secara lebih baik daripada para pesaingnya. Demikian pula, mendiferensiasikan diri dengan cara memberikan ciri lebih banyak kepada produk barangkali membutuhkan biaya lebih tinggi daripada mendiferensiasikan diri dengan cara memberi produk cirri yang berbeda-beda tetapi lebih disukai (Porter, 1993).

\section{B. Analisis SWOT}

Analisis SWOT adalah analisis kondisi internal maupun eksternal suatu 
organisasi yang selanjutnya akan digunakan sebagai dasar untuk merancang strategi dan program kerja. Analisis internal meliputi peniaian terhadap faktor kekuatan (Strength) dan kelemahan (Weakness). Sementara, analisis eksternal mencakup faktor peluang (Opportunity) dan tantangan (ThreathS). Menurut Rangkuti, (2009) Analisis SWOT adalah proses identifikasi berbagai faktor secara sistematis guna menentukan rumusan yang tepat dan melakukan strategi perusahaan yang terbaik. Analisis ini berdasarkan pada logika yang dapat memaksimalkan kekuatan (Strengths) dan peluang (Opportunities), namun secara bersamaan dapat meminimalkan kelemahan(Weaknesses) dan ancaman (Threats). Proses pengambilan keputusan strategis perusahaan selalu berkaitan erat dengan pengembangan misi, visi, tujuan, strategi serta kebijakan perusahaan. Oleh karenanya perencanaan yang strategis sangat memerlukan analisa-analisa dari masing masing SWOT ini (kekuatan, kelemahan, peluang, dan ancaman) di lingkungan perusahaan saat ini. Menurut Jogiyanto (2005) SWOT sangat diperlukan dalam menilai kekuatankekuatan maupun kelemahan-kelemahan dari sumber-sumber daya yang dimiliki oleh perusahaan serta menilai kesempatan-kesempatan eksternal maupun tantangan-tantangan yang dihadapi. David, (2005) memberi penjelasan mengenai SWOT sebagai berikut :
1. Strengths (Kekuatan)

2. Weakness (Kelemahan)

3. Opportunities (Peluang)

4. Threats (Ancaman)

Manfaat Analisis SWOT adalah menjadi metode analisis paling dasar untuk melihat suatu permasalahan di dalam perusahaan dilihat dari 4 sisi berbeda. Hasil analisis SWOT ini berupa rekomendasi atau arahan antara lain seperti mempertahankan kekuatan dan menambah keuntungan dari peluang yang ada. sambil mengurangi kekurangan dan juga menghindari ancaman. Analisis SWOT ini akan berguna dengan baik jika digunakan dengan benar. Dimana banyak sisi-sisi terlupakan dan tidak terlihat dalam perusahaan akan muncul dalam analisis SWOT ini. Sehingga Analisis SWOT ini sangat bermanfaat sebagai analisis strategi untuk meminimalisir kelemahan perusahaan / organisasi dan dapat menekan dampak ancaman yang muncul.

Pendekatan kualitatif matriks SWOT sebagaimana dikembangkan oleh Kearns menampilkan delapan kotak, yaitu dua paling atas adalah kotak faktor eksternal (Peluang dan Tantangan) sedangkan dua kotak sebelah kiri adalah faktor internal (Kekuatan dan Kelamahan). Empat kotak lainnya merupakan kotak isu-isu strategis yang timbul sebagai hasil titik pertemua antara faktor-faktor internal dan eksternal. 
Matriks SWOT Kearns

\begin{tabular}{|c|c|c|}
\hline INTERNAL & OPPORTUNITY & TREATHS \\
\hline STRENGTH & $\therefore$ Comparative & $\begin{array}{l}\text { Mobilization } \\
\therefore \therefore \therefore \therefore\end{array}$ \\
\hline WEAKNESS & Divestment/Investment & Damage Control. \\
\hline
\end{tabular}

Sumber: Hisyam, 1998

Keterangan:

Sel A: Comparative Advantages

Sel ini merupakan pertemuan dua elemen kekuatan dan peluang sehingga memberikan kemungkinan bagi suatu organisasi untuk bisa berkembang lebih cepat.

\section{Sel B: Mobilization}

Sel ini merupakan interaksi antara ancaman dan kekuatan. Di sini harus dilakukan upaya mobilisasi sumber daya yang merupakan kekuatan organisasi untuk memperlunak ancaman dari luar tersebut, bahkan kemudian merubah ancaman itu menjadi sebuah peluang.

\section{Sel C: Divestment/Investment}

Sel ini merupakan interaksi antara kelemahan organisasi dan peluang dari luar. Situasi seperti ini memberikan suatu pilihan pada situasi yang kabur. Peluang yang tersedia sangat meyakinkan namun tidak dapat dimanfaatkan karena kekuatan yang ada tidak cukup untuk menggarapnya. Pilihan keputusan yang diambil adalah (melepas peluang yang ada untuk dimanfaatkan organisasi lain) atau memaksakan menggarap peluang itu (investasi).

\section{Sel D: Damage Control}

Sel ini merupaka kondisi yang paling lemahdari semua sel karena merupakan pertemuan antara kelemahan organisasi dengan ancaman dari luar, dan karenanya keputusan yang salah akan membawa bencana yang besar bagi organisasi. Strategi yang harus diambil adalah Damage Control (mengendalikan kerugian) sehingga tidak menjadi lebih parah dari yang diperkirakan

\section{Hipotesis}

Hipotesis merupakan jawaban sementara terhadap rumusan masalah penelitian yang bertujuan mengarahkan dan memberikan pedoman dalam pokok permasalahan serta tujuan penelitian. Dengan demikian, dapat dimunculkan hipotesis penelitian sebagai berikut :

1. Diduga bahwa terdapat indikatorindikator dari analisis SWOT memeiliki pengaruh signifikan terhadap pengembangan strategi Jaxs Barbershop di Kota Makassar.

2. Diduga bahwa Jaxs Barbershop dapat mengembangkan strategi yang paling tepat diterapkan oleh Jaxs Barbershop berdasarkan anlisis SWOT.

\section{METODOLOGI PENELITIAN}

\section{A. Pendekatan Penelitian}

Penelitian ini menggunakan pendekatan secara kuantitatif. Metode ini akan menitiberatkan pada pengujian hipotsesis dengan menggunakan data terukur yang selanjutnya dapat ditarik sebuah kesimpulan.

\section{B. Populasi dan Sampel}

Populasi adalah kumpulan individu atau obyek penelitian yang memiliki kualitas-kualitas serta ciri-ciri yang telah ditetapkan. Berdasarkan kualitas dan ciri tersebut, populasi dapat dipahami sebagai sekelompok individu atau obyek pengamatan yang minimal 
memiliki satu persamaan karakteristik (Cooper dan Emory, 1998). Penelitian ini adalah penelitian populasi. Sedangkan populasi sasaran yang digunakan adalah karyawan Jaxs Barbershop yang berjumlah 13 orang

\section{Teknik Analisis}

Analisis data yang digunakan dalam penelitian ini adalah Pendekatan Kuantitatif Analisis SWOT. Data SWOT kualitatif dapat dikembangkan secara kuantitaif melalui perhitungan Analisis SWOT yang dikembangkan oleh Pearce dan Robinson (1998) agar diketahui secara pasti posisi organisasi yang sesungguhnya. Perhitungan yang dilakukan melalui tiga tahap, yaitu:

1. Melakukan perhitungan skor (a) dan bobot (b) point faktor serta jumlah total perkalian skor dan bobot $(\mathrm{c}=\mathrm{a}$ $\mathrm{x}$ b) pada setiap faktor S-W-O$\mathrm{T}$;Menghitung skor (a) masingmasing point faktor dilakukan secara saling bebas (penilaian terhadap sebuah point faktor tidak boleh dipengaruhi atau mempengeruhi penilaian terhadap point faktor lainnya. Pilihan rentang besaran skor sangat menentukan akurasi penilaian namun yang lazim digunakan adalah dari 1 sampai 10 , dengan asumsi nilai 1 berarti skor yang paling rendah dan 10 berarti skor yang peling tinggi. Perhitungan bobot (b) masing-masing point faktor dilaksanakan secara saling ketergantungan. Artinya, penilaian terhadap satu point faktor adalah dengan membandingkan tingkat kepentingannya dengan point faktor lainnya. Sehingga formulasi perhitungannya adalah nilai yang telah didapat (rentang nilainya sama dengan banyaknya point faktor) dibagi dengan banyaknya jumlah point faktor).

2. Melakukan pengurangan antara jumlah total faktor S dengan W (d) dan faktor $\mathrm{O}$ dengan $\mathrm{T}$ (e); Perolehan angka $(\mathrm{d}=\mathrm{x})$ selanjutnya menjadi nilai atau titik pada sumbu $X$, sementara perolehan angka $(e=y)$ selanjutnya menjadi nilai atau titik pada sumbu Y.

3. Mencari posisi organisasi yang ditunjukkan oleh titik $(\mathrm{x}, \mathrm{y})$ pada kuadran SWOT.

\begin{tabular}{|l|l|l|l|l|}
\hline No, & STRENGTH & SKOR & BOBOT & TOTAL \\
\hline 1. & & & & \\
\hline 2. & dst & & & \\
\hline & Total Kekuatan & & & \\
\hline & & SKOR & BOBOT & TOTAL \\
\hline No. & WEAKNESS & & & \\
\hline 1. & & & & \\
\hline 2. & & & & \\
\hline \multicolumn{5}{|c|}{ Total Kelemahan } \\
\hline
\end{tabular}

\begin{tabular}{|l|l|l|l|l|}
\hline No, & OPPORTUNITY & SKOR & BOBOT & TOTAL \\
\hline 1. & & & & \\
\hline 2. & dst & & & \\
\hline & Total Peluang & & & \\
\hline & & SKOR & BOBOT & TOTAL \\
\hline No. & TREATH & & & \\
\hline 1. & & & & \\
\hline 2. & dst & & & \\
\hline \multicolumn{5}{|c|}{ Total Tantangan } \\
\hline \multicolumn{4}{|c|}{ Selisih Total Peluang - Total Tantangan $=\mathrm{O}-\mathrm{T}=\mathrm{y}$} \\
\hline
\end{tabular}




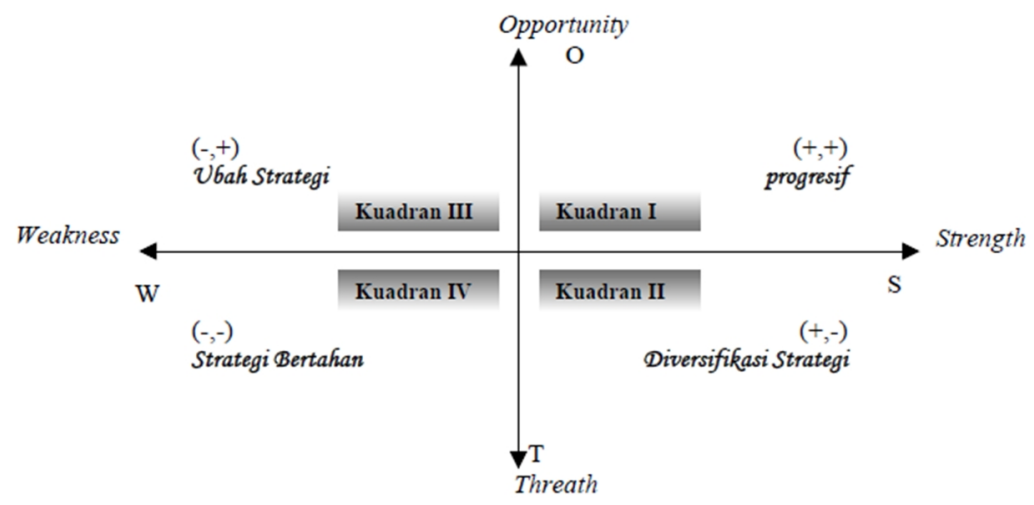

a. Kuadran I (positif, positif)

Posisi ini menandakan sebuah organisasi yang kuat dan berpeluang, Rekomendasi strategi yang diberikan adalah Progresif, artinya organisasi dalam kondisi prima dan mantap sehingga sangat dimungkinkan untuk terus melakukan ekspansi, memperbesar pertumbuhan dan meraih kemajuan secara maksimal.

b. Kuadran II (positif, negatif)

Posisi ini menandakan sebuah organisasi yang kuat namun menghadapi tantangan yang besar. Rekomendasi strategi yang diberikan adalah Diversifikasi Strategi, artinya organisasi dalam kondisi mantap namun menghadapi sejumlah tantangan berat sehingga diperkirakan roda organisasi akan mengalami kesulitan untuk terus berputar bila hanya bertumpu pada strategi sebelumnya. Oleh karenya, organisasi disarankan untuk segera memperbanyak ragam strategi taktisnya.

c. Kuadran III (negatif, positif)

Posisi ini menandakan sebuah organisasi yang lemah namun sangat berpeluang. Rekomendasi strategi yang diberikan adalah Ubah Strategi, artinya organisasidisarankan untuk mengubah strategi sebelumnya. Sebab, strategi yang lama dikhawatirkan sulit untuk dapat menangkap peluang yang ada sekaligus memperbaiki kinerja organisasi.

d. Kuadran IV (negatif, negatif)

Posisi ini menandakan sebuah organisasi yang lemah dan menghadapi tantangan besar. Rekomendasi strategi yang diberikan adalah Strategi Bertahan, artinya kondisi internal organisasi berada pada pilihan dilematis. Oleh karenanya organisasi disarankan untuk meenggunakan strategi bertahan, mengendalikan kinerja internal agar tidak semakin terperosok. Strategi ini dipertahankan sambil terus berupaya membenahi diri..

\section{HASIL PENELITIAN DAN PEMBAHASAN}

Data dari perusahaan Jaxs Barbershop yang telah dikumpulkan dan dilakukan analisis pada faktor internal dan eksternal kemudian digunakan untuk menentukan faktor strategi perusahaan untuk analisis SWOT. Faktor internal dan eksternal pelaksanaan pada Jaxs Barbershop sebagai berikut:

1. Kekuatan, 1) Dikenal di kalangan masyarakat, 2) Memiliki suasana ruangan yang baik, 3) Pelayanan prima, 4) Jaminan kualitas jasa bagi konsumen, 5) Memiliki capster yang ahli.

2. Kelemahan, 1) Tingkat harga jasa yang tinggi, 2) Antian panjang, 3) Lokasi yang kurang strategis, 4) Belum ada fasilitas cukur online, 5) Style rambut yang sama dengan pesaing.

3. Peluang, 1) Kemampuan menangkap pangsa pasar yang baik, 2) Citra perusahaan yang baik dimata konsumen, 3) Tingkat daya beli masyarakat, 4) Tingkat permintaan pasar, 5) Respon jasa yang baik dari masyarakat .

4. Ancaman, 1) Tingkat persaingan 
yang tinggi, 2) Pesaing menawarkan harga yang lebih murah, 3) Tingkat pertumbuhan barbershop yang tinggi, 4) Tuntutan pasar dalam update style rambut, 5) Bisnis cukur online.

\section{A. Pemberian bobot}

Pemberian bobot pada faktor internal dan eksteraal didasarkan pada penyebaran angket yang telah dilakukan pada karyawan Jaxs Barbershop. Ratarata dari faktor internal dan eksternal yang diperoleh atas pendapat karyawan sebagai berikut:

TABEL BOBOT ITEM FAKTOR INTERNAL JAXS BARBERSHOP

\begin{tabular}{|l|l|l|l|}
\hline NO & INDIKATOR & BOBOT & $\begin{array}{l}\text { Bobot } \\
\text { item }\end{array}$ \\
\hline & KEKUATAN & & \\
\hline & Di kenal di kalangan masyarakat & 3,6 & 0,12 \\
\hline & Memiliki suasana ruangan yang baik & 3,4 & 0,11 \\
\hline & Pelayanan yang baik & 3,7 & 0,12 \\
\hline & Jaminan kualitas jasa bagi konsumen & 3,6 & 0,12 \\
\hline & Memiliki capster yang ahli & 3,5 & 0,11 \\
\hline & KELEMAHAN & & \\
\hline & Tingkat harga jasa yang tinggi & 2,8 & 0,09 \\
\hline & Antrian panjang & 2,3 & 0,08 \\
\hline & Lokasi yang kurang strategis & 2,6 & 0,09 \\
\hline & Belum ada fasilitas cukur online & 2,7 & 0,09 \\
\hline & Style rambut yang sama dengan pesaing & 2,5 & 0,08 \\
\hline & Total & 1,00 \\
\hline
\end{tabular}

Hasil pada kolom bobot item total faktor eksternal yaitu penjumlahan indikator peluang dan ancaman diperoleh dari nilai bobot pada setiap indikator peluang dan ancaman dibagi bobot peluang dan ancaman dengan jumlah 29,6. Secara singkat bobot item= (bobot: 29,6).

TABEL BOBOT ITEM FAKTOR EKSTERNAL JAXS BARBERSHOP

\begin{tabular}{|l|l|l|l|}
\hline NO & INDIKATOR & BOBOT & $\begin{array}{l}\text { Bobot } \\
\text { item }\end{array}$ \\
\hline & PELUANG & & \\
\hline $\begin{array}{l}\text { Kemampuan menangkap pangsa pasar yang } \\
\text { baik }\end{array}$ & 3,3 & 0,11 \\
\hline & Citra perusahaan yang baik dimata & 3,6 & 0,12 \\
\hline & Tingkat daya beli masyarakat & 3,4 & 0,11 \\
\hline & Tingkat permintaan pasar & 3,4 & 0,11 \\
\hline & Respon jasa yang baik dari konsumen & 3,5 & 0,12 \\
\hline & ANCAMAN & & \\
\hline & Tingkat persaingan tinggi & 2,7 & 0,09 \\
\hline & Pesaing menawarkan harga yang lebih & 2,4 & 0,08 \\
\hline & Tingkat pertumbuhan barbershop yang & 2,5 & 0,08 \\
\hline & Tuntutan pasar dalam update style rambut & 2,4 & 0,08 \\
\hline & Bisnis cukur online & 2,5 & 0,09 \\
\hline & Total & & 1,00 \\
\hline
\end{tabular}

\section{B. Pemberian Rating}

Nilai rating diberikan dengan meminta bantuan manajer Jaxs Barbershop sebagai patokan. Hasil pemberian rating sebagai berikut: 
Tabel Rating Internal Dan Eksternal Jaxs Barbershop

\begin{tabular}{|l|l|l|}
\hline NO & INDIKATOR & RATING \\
\hline 1 & FAKTOR KEKUATAN & 4 \\
\hline 2 & Dikenal dikalangan masyarakat & 3 \\
\hline 3 & Memiliki suasana ruangan yang baik & 4 \\
\hline 4 & Jelayanan prima & 4 \\
\hline 5 & Memiliki capster yang ahli & 4 \\
\hline NO & FAKTOR KELEMAHAN & RATING \\
\hline 1 & Tingkat harga jasa yang tinggi & 2 \\
\hline 2 & Antrian panjang & 2 \\
\hline 3 & Lokasi yang kurang strategis & 1 \\
\hline 4 & Belum ada fasilitas cukur online & 4 \\
\hline 5 & Style rambut yang sama dengan pesaing & 4 \\
\hline NO & FAKTOR PELUANG & RATING \\
\hline 1 & Kemampuan menangkap pangsa pasar yang baik & 3 \\
\hline 2 & Citra perusahaan yang baik dimata konsumen & 4 \\
\hline 3 & Tingkat daya beli masyarakat & 3 \\
\hline 4 & Tingkat permintaan pasar & 3 \\
\hline 5 & Respon jasa yang baik dari masyarakat & 4 \\
\hline NO & FAKTOR ANCAMAN & RATING \\
\hline 1 & Tingkat persaingan tinggi & 2 \\
\hline 2 & Pesaing menawarkan harga yang lebih murah & 4 \\
\hline 3 & Tingkat pertumbuhan barbershop yang tinggi & 2 \\
\hline 4 & Tuntutan pasar dalam style rambut & 3 \\
\hline 5 & Bisnis cukur online & 4 \\
\hline
\end{tabular}

Penentuan strategi pada Jaxs Barbershop dalam menghadapi persaingan. Identifikasi pada faktor internal dan eksternal pada "Jaxs Barbershop" setelah dianalisis, kemudian diberikan bobot atau rating. Hasil analisis yang telah dilakukan pada Jaxs Barbershop yang dapat digunakan dalam penentuan strategi.

Total bobot item INTERNAL STRATEGI FACTOR ANALYSIS JAXS BARBERSHOP (IFAS) rating yang bernilai 3,30 diperoleh dari penjumlahan bobot item diperkalikan dengan rating faktor kekuatan dan kelemahan. Total bobot EKSTERNAL STRATEGI FACTOR ANALYSIS JAXS BARBERSHOP (EFAS) item diperkalikan rating yang bernilai 3,23 diperoleh dari penjumlahan bobot item diperkalikan rating faktor kekuatan dan kelemahan.

IFE Matrix dan EFE Matrix

merupakan kondisi relatif yang dihadapi oleh Jaxs Barbershop. Kondisi-kondisi inilah yang mereka hadapi dalam menjalankan usaha,

\section{Diagram SWOT (Strength, Weakness, Opportunity, Threats)}

Berdasarkan hasil analisis terhadap variabel yang rating dan bobot sesuai dengan kriteria faktor strategi internal yang telah ditentukan, maka diperoleh hasil bahwa nilai bobot dikalikan rating atas faktor kekuatan senilai 2,20 dan nilai kelemahan senilai 1,10 sehingga dapat disimpulkan bahwa nilai bobot kekuatan lebih besar senilai (positi) 1,10 dari kelemahan yang ada dengan perhitungan sebagai berikut: $S=$ $2,20 \mathrm{~W}=1,10$ dan $\mathrm{S}-\mathrm{W}=1,10$.

Berdasarkan hasil analisis terhadap variabel yang rating dan bobot sesuai dengan kriteria faktor strategi eksternal yang telah ditentukan, maka diperoleh hasil bahwa nilai bobot dikalikan rating atas faktor peluang senilai 1,98 dan nilai ancaman senilai 1,25 sehingga dapat disimpulkan bahwa nilai bobot peluang lebih besar senilai (positif) 0,73 dari ancaman yang ada 
dengan perhitungan sebagai berikut: $\mathrm{O}=$ $1,98 \mathrm{~T}=1,25$ dan $\mathrm{O}-\mathrm{T}=0,73$.

Berdasarkan hasil analisis perbandingan kekuatan (S) dan

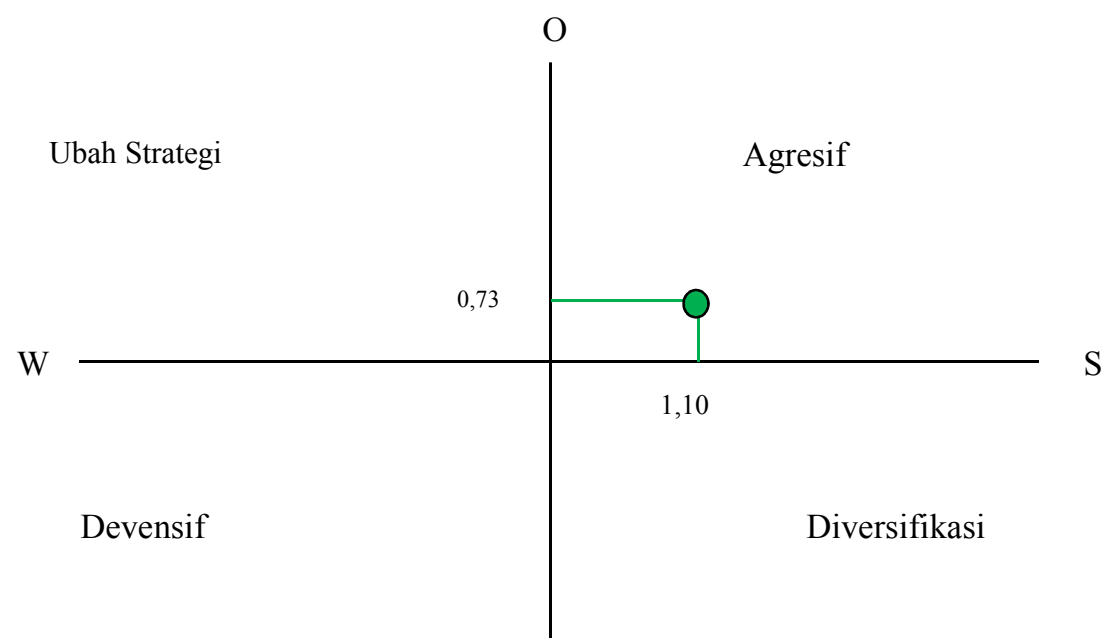

$\mathrm{T}$

Dari hasi analisis data yang diperoleh, menunjukkan bahwa Jaxs Barbershop memiliki bobot nilai yang baik dalam lingkungan eksternalnya yaitu berada pada posisi opportunities, sehingga dapat disimpulkan bahwa posisi persaingan Jaxs Barbershop menurut diagram SWOT berada pada kuadran 1 (satu) yaitu SO, yang menunjukkan Jaxs Barbershop ini memiliki peluang dan kekuatan sehingga dapat memanfaatkan peluang yang ada. Menurut Rangkuti (2016) bahwa pada kuadran 1 (Satu) mendukung strategi agresif. Strategi yang dihasilkan adalah penetrasi pasar, pengembangan pasar, defersifikasi.

\section{SIMPULAN DAN SARAN}

\section{A. Simpulan}

Berdasarkan hasil penelitian dan pembahasan, maka di tarik kesimpulan sebagai berikut:

1. Hasil analisis data faktor internal yaitu 3,30 didapat dari total penjumlahan rating faktor kekuatan dan kelemahan perusahaan. Nilai 3,30 memiliki arti nilai tersebut tinggi dengan penilaian skala likert. Nilai kekuatan paling tinggi terdapat pada poin pelayanan prima kelemahan (W) dan peluang (O) dengan ancaman (T) maka dapat digunakan untuk mengambarkan diagram SWOT Jaxs Barbershop. terhadap kelangsungan usaha dengan bobot 3,7 atau bobot item 0,12 ini menunjukkan bahwa pelayanan Jaxs Barbershop berpengaruh besar terhadap kelangsungan usaha. Nilai kelemahan paling tinggi terdapat pada poin tingkat harga jasa yang tinggi dengan bobot 2,8 atau bobot item 0,09 ini menunjukkan bahwa tingkat harga yang ditawarkan Barbershop kepada konsumen masih tinggi.

2. Hasil analisis data nilai faktor eksternal yaitu 3,23 didapat dari penjumlahan rating faktor peluang dan ancaman perusahaan. Nilai 3,23 memiliki arti nilai tersebut tinggi dengan penilaian skala likert. Nilai peluang paling tinggi pada poin citra perusahaan yang baik dengan bobot 3,6 atau bobot item 0,12 ini menunjukkan bahwa Jaxs Barbershop memiliki citra yang baik di dimata masyarakat.

3. Berdasarkan hasil olah data, diketahui bahwa nilai bobot yang Jaxs Barbershop dalam kuadran SWOT berada pada kudran satu 
yang berarti mendukung strategi agresif.

\section{B. Saran}

Penelitian ini dapat dikembangkan untuk meneliti obyek yang lebih luas. Untuk penelitian mendatang, pengembangan indikator hendaknya dilakukan untuk mendapatkan hasil yang lebih akurat. Penelitian disarankan pula untuk dilakukan pada obyek lain untuk menilai kehandalan dan ketepatan instrumen penelitian.

\section{DAFTAR PUSTAKA}

Cooper, Donald R., dan C. William Emory, 1998. Metode Penelitian Bisnis. Erlangga, Jakarta.

Cravens, Davis W. 1996. Pemasaran Strategis (Terjemahan), Erlangga, Jakarta.

Dan Schendel dan Charles Higgins. $1985 . \quad$ Pengambilan Keputusan Stratejik Untuk organisasi public dan Organisasi Non Profit. Jakarta Grasindo.

David, Fred R., 2004, Manajemen Strategi : Konsep. Jakarta PT Prenhalindo.

Getz, Gary A. dan Frederick D. Sturdivant, 1989. The Nuts and Bolts of FormulatingDifferentiation Strategy. Planning Review $17(5): 4-9$.

Hisyam, M.S. (1998). Analisa SWOT Sebagai Langkah Awal Perencanaan Usaha. Makalah. Jakarta : SEM Institute.
Jogiyanto. 2005. Analisis dan Desain Sistem Informasi Yogyakarta: Penerbit Andi.

Mac. Millan, Ian C. dan Rita Gunther McGrath, 1997. Discovering New Points of Differentiation. Harvard Business Review : 133 138.

Porter, Michael E., 1993. Keunggulan Bersaing - Menciptakan dan Mempertahankan Kinerja Unggul. Erlangga, Jakarta.

Bersaing $\quad: \quad$ Ttrategi
Menganalisa Industri dan
Pesaing, Erlangga, Jakarta.

Rangkuti, Freddy., 1998., Analisis Swot Teknik Membedah Kasus Bisnis., Gramedia Pustaka Utama, Jakarta.

Umar, Husein. 2002. Strategic management in action : konsep, teori, dan Teknik Menganalisa manajemen strategis strategic business unit berdasarkan konsep michael R. David, danWheelen-Hunger. Jakarta: Gramedia.

Pearce, J.A.II., dan Robinson, R.B.Jr., (1998). Manajemen Strategis. Jakarta : Binarupa Aksara.

Wahyudi, Agustinus Sri., 1996., Manajemen Strategik (Pengantar proses berpikir. Strategik)., Binarupa Aksara, Jakarta. 